\title{
Let a hundred flowers bloom; let a hundred schools of thought contend
}

\author{
Gerry Stahl • Friedrich Hesse
}

Published online: 21 April 2011

(C) International Society of the Learning Sciences, Inc.; Springer Science+Business Media, LLC 2011

The title of this editorial is translated from a Chinese poem. The words have been adopted, adapted, reinterpreted, repurposed, proclaimed, and misquoted repeatedly since 1956, when they were popularized in the context of the Chinese revolution and its international reception. In re-contextualizing the original spirit of the poetic line within the current situation of the CSCL research field, we strive to foster, articulate, and support openness within our community to multiple schools of thought. In particular, ijCSCL provides a venue for exploration of alternative perspectives and for dialog among them.

While each CSCL researcher necessarily favors specific paradigms-more or less selfconsciously - the field itself profits from a cacophony of voices: theoretical, methodological, pedagogical, technological, ideological, political, interdisciplinary, and international. Scientific revolutions - like political revolutions - advance through the confrontation of viewpoints and the critique of established paradigms. We can see this in the academic progress of our field as clearly as on the battlefronts of the Middle East. While dominant positions may facilitate short-term ends, they restrict innovative thinking and practices; they are eventually surpassed and their rules overthrown.

Educational systems around the world are still striving to implement an industrial-era view of knowledge as factual content and learning as the testable transfer of knowledge from authoritative sources to individual students. CSCL is defined by alternative views, in which knowledge can be co-constructed by small groups and communities, particularly with the support of networked computers. Since its inception, CSCL research has built upon a wide variety of established and innovative approaches to pedagogy, theory, analysis, and technology. Through this open-inquiry approach, the CSCL field itself adopts the attitude of letting many flowers bloom, which it projects as definitive of a stance toward learning that is appropriate to the contemporary post-industrial world.

G. Stahl $(\bowtie)$

Drexel University, Philadelphia, PA, USA

e-mail: Gerry@ijCSCL.org

F. Hesse

Knowledge Media Research Center, Tubingen, Germany 
The field of CSCL began as a multi-disciplinary effort, bringing together diverse concerns and approaches to the complex task of achieving the promise of computersupported collaborative learning in actual school classrooms. Rather than converging on a single approach, the research community has increasingly recognized the need to incorporate more and more considerations. The goal of CSCL is inherently multifaceted. It must account for psychological, pedagogical, technological, and community-based phenomena. It must design for individual, small-group, and classroom interactions. It must overcome barriers involving entrenched beliefs and practices of students, parents, teachers, principals, school districts, and governmental policies. Moreover, for each of these aspects, there are competing, apparently incommensurable ways of analyzing, understanding, and responding. This is the nature of the CSCL mission; the journal of CSCL must provide a fertile ground in which a rich ecology of schools of thought can germinate and flourish.

In this issue, we offer a bouquet of diverse CSCL investigations, focused on promising approaches to educational practice, interactional theory, collaboration analysis, and technology design. Each of these studies is grounded in traditional disciplinary foundations, but each also strains toward a future of innovative possibilities. Together, they foreshadow some of the presentations scheduled for the impending CSCL 2011 Conference.

\section{A flower garden in Hong Kong}

The conference - to take place in Hong Kong this July-has the theme, "Connecting computer-supported collaborative learning to policy and practice." As befitting this theme, our opening article by Carol K. K. Chan discusses the extended efforts of a group of researchers and teachers in Hong Kong to connect CSCL insights and approaches to the local educational policy and practice. This account complements the lead article last issue, reporting similar work in Singapore.

As noted by the video commentaries on the PISA results - cited in the introduction to the previous issue (Stahl and Hesse 2011) — the most striking factor in leading educational systems such as those of Finland and Shanghai is the support given teachers by their peers. So it is particularly fortunate that the presentation here focuses on the Hong Kong Knowledge-Building Teachers Network (KBTN).

KBTN is a meeting place of forward-looking government policy initiatives, teacher peer support, CSCL researcher initiative, well-established CSCL theory, and the use of CSCL technology. KBTN has been funded continuously since 2006 by the Hong Kong Ministry of Education, in accordance with their educational reforms going back to 2000. As you can tell from its name, KBTN is based on the theory of knowledge building. This was a pioneering theory in the history of CSCL (Scardamalia and Bereiter 1991), and involved the development of one of the first explicitly CSCL software environments, Knowledge Forum. The author, Carol Chan, conducted research in Scardamalia and Bereiter's Toronto lab before going to the University of Hong Kong. The KBTN is part of their broader effort to build an International Institute for Knowledge Innovation and Technology (IKIT).

Chan provides a stimulating and thoughtful reflection on the development of the KBTN. Recognizing the complexity and situatedness of the effort to support teachers in adopting a knowledge-building pedagogy and adapting it to the Hong Kong context, Chan parallels last issue's strategy by Looi et al. (2011) to analyze the macro, meso, and micro levels of transformation as well as their mutual interactions, as already proposed in the first issue of this journal (Jones et al. 2006). She provides an action researcher's perspective on the issues that arose and how they evolved over the years. Wisely, she refrains from any final 
evaluation or recommendation, recognizing that the effort is ongoing and that its lessons must be resituated in other settings.

Despite similarities in format of the reports from Singapore and Hong Kong, the differences are also striking. Especially if one considers them in the context of previous descriptions of teacher adoption of knowledge-building pedagogy, theory, and technology in other countries like Canada, Finland, or Italy, they appear as unique flowerings in a field of diversity. For instance, in Singapore the impetus came from the government, whereas in Hong Kong it was driven more by researchers and teachers. In Hong Kong, they introduced a relatively mature technology into the classrooms, while in Singapore they were more concerned with evolving the technology design. However, in both reports we find concerns that are familiar within CSCL research and seem to confront most efforts to transform traditional schooling into computer-supported collaborative learning.

Having contrasted a pair of studies of CSCL practice, we will continue in this issue with pairs of counter-poised papers on CSCL theory, analysis, and technology.

\section{An intersubjective dialogical space or an individual's cognitive conflict?}

CSCL is distinctive within the learning sciences by virtue of its focus on collaboration, the process by which multiple people learn together. In this, it is inspired by: (a) the earlier work on cooperative learning, which determined the learning outcomes for individual students as a consequence of being involved with small groups (Johnson and Johnson 1989); (b) Vygotsky's insight that individual cognition is derivative of intersubjective experiences (Vygotsky 1930/1978); and (c) Lave's perspective on learning as participation in a community of practice (Lave 1991). Subsequent theories relevant to CSCL have accordingly fore-fronted (a) the individual, (b) the small group, or (c) the community level of analysis as the site of learning. Of course, a full analysis must take into account all three levels and their essential interpenetration, but any given analyst is usually well advised to focus on one level, in accordance with a specific research interest.

A prominent tendency within CSCL studies oriented to the small-group cognitive unit is that associated with dialogicality; the paper by Manoli Pifarre and Judith Kleine Staarman can be viewed in that vein. Analyzing an experiment conducted in Spain, the authors build on the theoretic and analytic work of their British colleagues Mercer (Kershner et al. 2010) and Wegerif (2006). They investigate how a wiki environment can provide a "dialogic space" for group knowledge building (see also Glassman and Kang 2011; Larusson and Alterman 2009). They note that the wiki gave voice to each participant, having them start by posting their own ideas; with the use of a "thinking together" approach based upon "exploratory talk," the wiki allowed the students to create a "dialogic space" to co-construct new understanding; the resulting wiki content served as a shared digital artifact as the product of their collaboration. The co-construction processes engaged in by the students involved them in taking into account each other's opinions, thereby reaching new intersubjective understandings and appreciations.

By contrast, the information-processing perspective developed by Robert L. Jorczak can be taken as representative of an approach that always traces the analysis to the level of individual cognition. This paper defends the view that was dominant in the beginnings of the CSCL field - influenced by artificial intelligence and cognitive science exploring the analogy between human thought and computer heuristic algorithms. While the informationprocessing model was originally focused on certain forms of problem solving by isolated individuals, it is here extended with the help of Piagetian concepts of cognitive conflict or 
internalization/externalization (Cress and Kimmerle 2008; Mugny et al. 1975) to account for the individual learning that can result from small-group interaction. With its Collaborative Information Processing model, this paper conceptualizes group processes as consisting of flows of information in and out of individual minds, through which individuals accept divergent ideas and potentially respond with convergent ideas. The productive tension of cognitive conflict at the group level is thereby reduced to individual processing of information via internalization and externalization.

Jorczak reviews a variety of theoretical approaches, including those that emphasize group-level, fundamentally interactional processing such as clarification, elaboration, and conceptual-conflict resolution. He specifically interprets an early version of (Stahl 2000) as a model of how group processes arise from and then feed into individual cognitive processes. But that model was intended to show how the individual processes contribute to the group processes - within which they must be conceptualized - as perhaps more clearly pictured in the republication (Stahl 2006, Ch. 9, esp. pp. 210-11) and more recently in (Stahl 2010, p. 256). The conceptualization of cognition as information processing may lead to the view that information processed by a group is simply an input into individual cognitive processing and learning. But the larger question is whether there are group processes that are central to collaborative learning but that are not reducible to aggregations of individual information processing. Is the dialogical space, for instance, as intersubjective, greater than the sum of the contributions to it? If a dialog context emerges from interaction of multiple subjects, do group phenomena or practices take place that should be attributed to or interpreted as group-cognitive processes? When Hutchins (1996) analyzes the information flows through a complex socio-technical system involving a skilled team, well established practices, historically developed navigational artifacts, and systematic training regimens, does the accomplishment of navigating the ship essentially exceed the sum of the individual-cognitive processes that contribute to it? The theoretical question may be an empirical one, requiring detailed case studies like Hutchins'. We now turn to such analysis.

\section{A mental representation or a co-referential gesture?}

The next two articles provide contrasting approaches to analyzing individual and group processes. First, we have a thorough quantitative experimental study of the effect of representational formats on individual and collaborative behaviors by Bas Kolloffel, Tessa H. S. Eysink, and Ton de Jong. Although the study was conducted in actual classrooms, the experiment was designed with the rigor of a lab study. Students were divided into individual and collaborative (dyad pair) settings, each of which was randomly divided into conditions using three different representational formats (concept maps, textual summaries, mathematical equations). A series of hypotheses based on previous studies was then systematically tested through statistical comparisons among conditions, using pre- and posttests of individual student understanding. Although the study was intended to explore collaborative inquiry learning, the inquiry took place in a quite restrictive interface, in which mathematical problems with well-defined answers were presented and even analyzed for the students. The collaboration (in the dyad setting) was unstructured talk, which was not captured or analyzed. While some hypotheses were confirmed and others were not, the explanation of these results was left for speculation. Even though the effect of certain representations appeared to be different in the individual and dyadic settings, there was no way to know what role the representations may have played in dyad discussion or how the representations may have been differently understood by individuals and dyads. 
Discussions of diversity in analysis methods often argue for the superiority of either "quantitative" or "qualitative" approaches. Increasingly, this has become recognized to be a false dichotomy. In general, methods have to be selected, adapted, or created depending on the nature of the data and the driving research interests. Additionally, a combination of "mixed methods" is becoming common. Often, a statistical analysis can suggest or even confirm a hypothesis, but then a close inspection of how an individual interaction took place may be needed to indicate underlying mechanisms or processes, as the authors of the representation study note and promise in future work. On the other hand, since analysis of a single case can raise questions of typicality or generalizability, a statistical result may be needed to motivate the significance of the detailed analysis.

The next paper, by Michael Evans, Eliot Feenstra, Emily Ryon, and David McNeill, seeks to provide the analytic tools needed to analyze the kinds of collaborative interactions that take place around external representations and other mathematical manipulatives. In doing so, it addresses many of the questions raised above. It hones in on a core phenomenon in the building of intersubjectivity or distributed cognition: what it calls "coreferencing." This involves multiple people referencing the same thing, whether through a deictic word, a pointing gesture, or any other verbal, physical, or virtual action that references something as intended by more than one person. Simply by paying attention to co-referential actions within a dyadic interaction, an analyst can get a qualitative sense of the co-construction process and the shared experience of collaborative meaning making. If, as these authors do, one also develops and applies a coding scheme for tracking coreferences in discourse, then one can start to compile quantitative measures for possible comparison across cases. An important trend within Conversation Analysis - a prominent approach to the detailed analysis of interaction - has been to include the analysis of gesture along with talk, and McNeill's work on the coordination of gesture with word and thought (2006) has been influential there. In the paper here, a systematic typology of forms and levels of co-reference is sketched and a method of coding co-references in their temporality is proposed and illustrated.

\section{Adapting technology to interaction or adapting interaction with technology?}

Although many CSCL researchers specialize in collaborative-learning pedagogy, in analysis of interaction, or in the associated theory, for the field as a whole, the design of technology to provide the computer support for collaborative learning remains central. As the marketplace begins to offer media for collaboration, including Web 2.0 apps, CSCL designers still have to be concerned with how to adapt the generic media (discussion forums, chat, whiteboards, wikis, blogs, Facebook, etc.) to demanding educational goals and how to best structure the enactment of the technology in specific educational settings.

The report by Erin Walker, Nikol Rummel, and Kenneth R. Koedinger provides an insightful overview of some of the complexities involved in such adaptation. This work comes out of the Pittsburgh Science of Learning Center, home of the Cognitive Tutor Algebra. This paper takes that well-established technology for assisting individual students in learning algebra algorithms into the quite different realm of adapting such automated support to improve the quality of collaborative student interactions as two students take turns tutoring each other in mathematics. The reported attempt must be viewed as the start of several iterations. The authors recognize this. They have elaborated what they call an "in vivo" experimentation design process that combines design research with controlled experimentation to balance the tradeoffs between control and ecological validity. Similarly, 
they used mixed methods to get a full picture: without the qualitative data they would not understand why student use of conceptual help improved; but without the quantitative data they could not have determined how differences between isolated cases mapped to systematic contrasts between conditions.

The final article in the issue illustrates a social psychology approach, adapted to CSCL and the design of interaction. Here, Ulrike Cress, Katrin Wodzicki, Martina Bientzle, and Andreas Lingnau were interested in supporting communication among intellectually disabled students. A group task was set up in a German special school and a set of rules was defined for subject behaviors. Two conditions were defined by manipulating one of the rules, and the results were compared. The researchers hypothesized that structuring the communication with a "floor-control" mechanism could have a substantial effect on facilitating communication among intellectually disabled people. They scripted the goaldirected behavior so that the participants had to discuss the transfer of the right to relocate items that were to be rearranged. The interesting result from a methodological perspective is that the quantitative results of the experiment were impossible to interpret on their own, perhaps even misleading. It was only through a mixed-methods approach of looking closely at the log of a typical interaction from each condition that one could make sense of the results.

\section{References}

Cress, U., \& Kimmerle, J. (2008). A systemic and cognitive view on collaborative knowledge building with wikis. International Journal of Computer-Supported Collaborative Learning, 3(2), 105-122. doi:10.1007/s11412-007-9035-z

Glassman, M., \& Kang, M. J. (2011). The logic of wikis: The possibilities of the web 2.0 classroom. International Journal of Computer-Supported Collaborative Learning, 6(1), 93-112. doi:10.1007/ s11412-011-9107-y

Hutchins, E. (1996). Cognition in the wild. Cambridge: MIT Press.

Johnson, D. W., \& Johnson, R. T. (1989). Cooperation and competition: Theory and research. Edina: Interaction Book Company.

Jones, C., Dirckinck-Holmfeld, L., \& Lindström, B. (2006). A relational, indirect, meso-level approach to CSCL design in the next decade. International Journal of Computer-Supported Collaborative Learning, 1(1), 35-56. doi:10.1007/s11412-006-6841-7

Kershner, R., Mercer, N., Warwick, P., \& Staarman, J. K. (2010). Can the interactive whiteboard support young children's collaborative communication and thinking in classroom science activities? International Journal of Computer-Supported Collaborative Learning, 5(4) doi:10.1007/s11412-010-9096-2

Larusson, J., \& Alterman, R. (2009). Wikis to support the "collaborative" part of collaborative learning. International Journal of Computer-Supported Collaborative Learning, 4(4), 371-402. doi:10.1007/ s11412-009-9076-6

Lave, J. (1991). Situating learning in communities of practice. In L. Resnick, J. Levine, \& S. Teasley (Eds.), Perspectives on socially shared cognition (pp. 63-83). Washington: APA.

Looi, C.-K., So, H.-J., Toh, Y., \& Chen, W. (2011). CSCL in classrooms: The Singapore experience of synergizing policy, practice and research. International Journal of Computer-Supported Collaborative Learning, 6(1), 9-38. doi:10.1007/s11412-010-9102-8

McNeill, D. (2006). Gesture and thought. Chicago: University of Chicago Press.

Mugny, G., Doise, W., \& Perret-Clermont, A. N. (1975). Social interaction and the development of cognitive. European Journal of Social Psychology, 5(3), 367-383.

Scardamalia, M., \& Bereiter, C. (1991). Higher levels of agency in knowledge building: A challenge for the design of new knowledge media. Journal of the Learning Sciences, 1, 37-68.

Stahl, G. (2000). A model of collaborative knowledge-building. Paper presented at the Fourth International Conference of the Learning Sciences (ICLS '00). Ann Arbor, MI. Proceedings pp. 70-77: Lawrence Erlbaum Associates. Web: http://GerryStahl.net/pub/icls2000.pdf.

Stahl, G. (2006). Group cognition: Computer support for building collaborative knowledge. Cambridge, MA: MIT Press. $510+$ viii pages. Web: http://GerryStahl.net/mit/. 
Stahl, G. (2010). Guiding group cognition in CSCL. International Journal of Computer-Supported Collaborative Learning, 5(3), 255-258. doi:10.1007/s11412-010-9091-7

Stahl, G., \& Hesse, F. (2011). CSCL in Asia. International Journal of Computer-Supported Collaborative Learning, 6(1), 1-7. doi:10.1007/s11412-011-9112-1.

Vygotsky, L. (1930/1978). Mind in society. Cambridge: Harvard University Press.

Wegerif, R. (2006). A dialogic understanding of the relationship between CSCL and teaching thinking skills. International Journal of Computer-Supported Collaborative Learning, 1(1), 143-157. doi:10.1007/ s11412-006-6840-8 